\title{
Attitude and awareness of dental students and interns toward infection control measures in prosthodontic clinics
}

\author{
Ibraheem Fahad Alshiddi* \\ Department of Prosthetic Dental Sciences, College of Dentistry, King Saud University, Kingdom of Saudi Arabia
}

\begin{abstract}
Objectives: To evaluate the attitude and awareness of the dental students and interns toward infection control measures in prosthodontic clinic and to assess their satisfaction toward applying these measures during prosthodontic treatment.

Methods: A questionnaire study was conducted among 360 fourth and fifth dental students and interns (238 males and 122 females) in November 2014 in College of Dentistry, King Saud University, Riyadh, Saudi Arabia. It consisted of 30 close-ended questions related to vaccination status and previous sharp injuries, attitude and awareness towards infection control in prosthodontic clinic, previous education about infection control, and subjects' satisfaction about their knowledge and attitude. The questionnaire was sent to all students and interns by email to be filled electronically, and informed consent was obtained before commencing the questionnaire.

Results: Total of 258 (71.66\%) study subjects responded to the questionnaire. Their attitude and awareness toward infection control in prosthodontic clinic was varied between $100 \%$ were regularly using gloves with patient to $17.8 \%$ were regularly disinfect dental cast before sending it to dental laboratory. Most of the subjects responded "good" or "fair" to the two questions related to the evaluation of their knowledge and policy implementation of infection control in prosthodontic clinic
\end{abstract} $(\mathrm{P}<0.0001)$. Around $43 \%$ were almost satisfied and 36\% were fairly satisfied with their knowledge and performance.

Conclusions: Findings indicate insufficient attitude and awareness of subjects toward infection control in prosthodontic practice. Their self-assessment and satisfaction reflect their performance toward infection control policy.

\section{Introduction}

Human oral cavity is a very good environment for the transmission, inoculation and growth of a variety of agents that can be infectious or detrimental to others [1]. Hence, disease transmission can easily occur in dental clinics through various routes [2]. These include direct contact with blood, oral fluids, or other secretions; indirect contact with contaminated instruments, operatory equipment, or environmental surfaces; or contact with contaminants that are airborne. In dental practice, dentists frequently encounter patient blood and blood-contaminated saliva during dental procedures which make transmission greatest from patient to dentist $[3,4]$. This is the reason why infection control rules an integral part in dental practice.

Graduates in dental education worldwide necessitate a high level of medical training, clinical skills and knowledge on infection control [5]. Therefore, it is recommended that the importance of infection control is explained meticulously to students in their early years in dental education. This is also considered essential for them to adopt their learned attitudes and behaviors on infection control when they become professional dentists [6]. Presently, a large number of new dental personnel and dental undergraduate students are being trained in University hospitals where they can participate in rendering treatments to patients. Cross-contamination is indeed more probable in dental students compared with more experienced members of the dental team because studies have demonstrated that future dentists have not always adhered to infection control measures properly [7-11]. Since dentists have the duty to ensure that correct infection control procedures are followed when patients are treated, it is imperative to emphasize to the dental students the protocols essential in reducing the risk of infection both to themselves and to their patients [5].

The absence of a comprehensive and well planned institutional effort to teach infection control is also another factor because motivation should start from the institution where the students will acquire their training. The absence of structured programs to train the faculty contributes on why poor infection control measures become more profound. Since educational interventions are necessary for creating high standards of infection control, enhancing comprehension on its principles, improving compliance and developing positive attitudes toward blood borne pathogens infected individuals could be of great help [11]. Prosthodontic Clinic required a high degree of concern regarding cross infection through patients, personnel, unsterilized instruments and equipments. Prosthodontics treatment undertaken in the clinics should be supplemented by the laboratory, and hence cross infection chances have to be halted in both the fronts. Fabrication of prostheses for infectious disease carriers presents a cross-contamination hazard. Dental impressions, maxillo-mandibular registration bases and apparatus, trial and final prostheses are all exposed to contamination in the patient's mouth. Such items can spread infectious agents to the clinician, other patients and the staff of the dental laboratory [12-14].

Correspondence to: Ibraheem F Alshiddi, College of Dentistry, King Saud University, P.O. Box 60169 Riyadh 11545, Kingdom of Saudi Arabia, Tel: +966 (0)14677325; Fax: +966 (0)1 4679015, E-mail: ialshiddi@ksu.edu.sa

Key words: attitude, awareness, dental students, infection control, prosthodontics

Received: July 12, 2015; Accepted: August 13, 2015; Published: August 17, 2015 
There are previous studies conducted on infection control in dental clinic in general $[1-3,6,10-12]$. However, these studies did not cover some of the important infection control procedure in prosthodontic clinic. The aim of this study was to evaluate the attitude and awareness of the dental students and interns toward infection control measures in prosthodontic clinic, and to assess their satisfaction toward applying these measures in their prosthodontic clinic.

\section{Material and methods}

A questionnaire study was conducted among dental students (fourth year and fifth year) and interns of College of Dentistry, King Saud University, Riyadh, Saudi Arabia in November 2014. The sample comprised of 360 subjects: 122 fourth-year dental students, 100 fifthyear dental students and 138 interns. The questionnaire was reviewed and the study was ethically approved by the College of Dentistry Research Center, King Saud University, Riyadh, Saudi Arabia.

The questionnaire was formed by the author with the help of experts in the field (Prosthodontists in Prosthetic Dental Department and the Infection Control Committee of the same dental school). It was a selfadministered questionnaire consisting of 30 close-ended questions: two questions related to the demographic data (gender and academic level), three questions recording hepatitis $B$ virus (HBV) vaccination status and previous sharp injuries, 20 questions to assess the attitude and awareness towards infection control in prosthodontic clinic, two questions related to previous education in infection control during the graduate studies, and last three questions was assessing subjects' satisfaction about their knowledge and attitude. The questionnaire was sent to all students by emails to be filled electronically, and informed consent was obtained from each student before commencing the questionnaire. It was pretested on a random sample of dental students to insure practicability, validity, and interpretation of responses. The validity of the questionnaire was assessed by comparing data of 20 subjects on two occasions (test and re-test methods).

Data was analyzed using SPSS PC+ version 21.0 statistical software. Descriptive statistics (mean, standard deviation and percentages) were used to describe the quantitative and categorical variables. Student's $\mathrm{t}$-test for independent samples, and one-way analysis of variance was used to compare the mean values of quantitative outcome variable (attitude score) in relation to the categorical study variables. Posthoc test (Tukey) was used to observe the significance of pair wise comparison. A P-value of $<0.05$ was used to report the statistical significance of the results.

\section{Results}

A total of 258 (71.66\%) study subjects responded to the questionnaire: 114 (44.2\%) interns, 105 (40.7\%) fourth-year students and $39(15.1 \%)$ fifth-year students. The total number of males was 177 (68.6\%), and females were 81(31.4\%). Among them, 94.2\% were vaccinated for $\mathrm{HBV}$ and only $2.3 \%$ (6 subjects) were not vaccinated (Table 1). For the sharp and eye splashing injuries, $57 \%$ of the subjects were reported that they had sharp injury at least once, comparing to $30.2 \%$ affected with eye splashing injury (Table 1 ).
Distribution of responses of study subjects attitudes and awareness towards infection control in the prosthodontic clinic are varied between $100 \%$ were regularly using gloves with patients to $17.8 \%$ were regularly disinfecting dental cast before sending it to dental laboratory. Details of their responses are shown in Table 2.

In response to the two questions related to the education in infection control during the graduate studies, about $84.9 \%$ of the study subjects responded positively for having only few lectures during their undergraduate program. On the other hand, 53.5\% responded positively for attending only one clinical demonstration or hands on workshop about infection control during undergraduate program (Table 3).

Only $8.1 \%$ of study subjects had evaluated their knowledge as "very good" towards infection control in prosthodontic clinic, 59.3\% of them as "good" and $29.1 \%$ as "fair". Towards implementation of infection control policy in their prosthodontic clinical practice, only $4.7 \%$ had evaluated it as "very good", $51.2 \%$ as "good", $40.7 \%$ as "fair" and $3.5 \%$ as "poor". About $8.1 \%$ of them were totally satisfied, $43 \%$ were almost satisfied, $36 \%$ were fairly satisfied and $10.5 \%$ were little satisfied with their knowledge and their performance in infection control in the prosthodontic clinic practice (Table 4).

The comparison of subject's attitudes toward their knowledge was calculated using nominal scale according to their response to the two knowledge questions. When comparing the mean values of attitude scores towards infection control across 5-point nominal scale responses of having didactic (theory) lectures during under-graduate or internship program questions, it indicated higher statistical significant for the subjects who responded positively for having only few lectures during undergraduate program comparing to the study subjects who had responded to other options $(\mathrm{F}=7.37, \mathrm{P}<0.0001)$. However, there was no statistical significantly different across the 4-point nominal scale responses towards the question related to attending a clinical demonstration/hands on workshop about infection control during under-graduate program $(\mathrm{F}=1.67 ; \mathrm{P}=0.17)$.

The comparison of mean values of attitudes scores towards infection control across the 5-point ordinal scale responses of three satisfaction questions of infection control indicates statistical significant difference in the responses to all the three questions. The mean attitudes scores was statistically significantly higher in study subjects who had responded as "very good" to the two questions related to the evaluation of their knowledge and related to policy implementation of infection control in prosthodontic clinic $(\mathrm{F}=9.78 ; \mathrm{P}<0.0001 ; \mathrm{F}=20.39 ; \mathrm{P}<0.0001)$, when compared with study subjects who had responded as "good", "fair" and "poor" to these two questions of satisfaction ( $\mathrm{F}=9.78 ; \mathrm{P}<$ $0.0001 ; \mathrm{F}=20.39 ; \mathrm{P}<0.0001)$. For the mean value of subject's attitude scores related to their satisfaction of their knowledge and performance towards infection control in prosthodontic clinic, there was a higher significantly different for the subjects who had responded as "totally satisfied" comparing other subject's responses $(\mathrm{F}=8.13$; $\mathrm{P}<0.0001)$.

Table 1. Distribution of types of vaccines and types of injuries of study subjects.

\begin{tabular}{|c|c|c|c|}
\hline Variables & Yes & No & \multicolumn{1}{|c|}{ I don't know } \\
\hline HBV vaccination & $243(94.2 \%)$ & $9(2.3 \%)$ & $108(41.9 \%)$ \\
\hline Sharp injury & $147(57 \%)$ & $162(62.8 \%)$ & $3(1.2 \%)$ \\
\hline Eye splashing & $78(30.2 \%)$ & $18(7.0 \%)$ \\
\hline
\end{tabular}


Table 2. Distribution of responses of study subject's attitudes and awareness towards infection control in Prosthodontic clinic.

\begin{tabular}{|c|c|c|c|}
\hline \multirow{2}{*}{ Questions related to attitudes and awareness towards infection control } & \multicolumn{3}{|c|}{ Distribution of responses } \\
\hline & Yes & No & I don't know \\
\hline \multicolumn{4}{|l|}{ Do you regularly wear the following barrier during dental procedure in prosthodontic clinic? } \\
\hline - $\quad$ Gloves & $258(100 \%)$ & -- & --- \\
\hline - $\quad$ Face Mask & $249(96.5 \%)$ & $9(3.5 \%)$ & --- \\
\hline - $\quad$ Protective Glass & $189(73.3 \%)$ & $69(26.7 \%)$ & --- \\
\hline - $\quad$ Protective Gowns & $249(96.5 \%)$ & $9(3.5 \%)$ & -- \\
\hline - $\quad$ Head Cap (cover) & $93(36 \%)$ & $165(64 \%)$ & -- \\
\hline \multicolumn{4}{|l|}{ Do you (or your dental assistant) regularly disinfect the following items between patients? } \\
\hline - $\quad$ Rubber bowl & $138(53.5 \%)$ & $21(8.1 \%)$ & $99(38.4 \%)$ \\
\hline - $\quad$ Alginate mixing spatula & $156(60.5 \%)$ & $15(5.8 \%)$ & $87(33.7 \%)$ \\
\hline - $\quad$ Face bow & $204(79.1 \%)$ & -- & $54(20.9 \%)$ \\
\hline - $\quad$ Shade guide & $147(57.0 \%)$ & $21(8.1 \%)$ & $90(34.9 \%)$ \\
\hline \multicolumn{4}{|l|}{ When taking Primary (alginate) or final impression, Do you (or your dental assistant) } \\
\hline - Apply plastic (or rubber) barrier or apply disinfectant on impression gun between patients? & $183(70.9 \%)$ & $27(10.5 \%)$ & $48(18.6 \%)$ \\
\hline - Rinse the impression under running water immediately after being removed from patient's mouth? & $249(96.5 \%)$ & $6(2.3 \%)$ & $3(1.2 \%)$ \\
\hline - Apply disinfectant on the impression after being rinsed with water? & $249(96.5 \%)$ & $6(2.3 \%)$ & $3(1.2 \%)$ \\
\hline - When you apply the disinfectant on the impression, do you also apply it on the outer side of the tray? & $141(54.7 \%)$ & $81(31.4 \%)$ & $36(14 \%)$ \\
\hline \multicolumn{4}{|l|}{ Do you regularly disinfect the following items before sending it to dental laboratory? } \\
\hline - Dental Cast & $46(17.8 \%)$ & $198(76.7 \%)$ & $14(5.4 \%)$ \\
\hline - $\quad$ Denture prosthesis & $177(68.6 \%)$ & $66(25.6 \%)$ & $15(5.8 \%)$ \\
\hline - Metal framework for removable or fixed prosthesis after try in & $177(68.6 \%)$ & $63(24.4 \%)$ & $18(7.0 \%)$ \\
\hline - Bite registration or wax rim & $168(65.1 \%)$ & $63(24.4 \%)$ & $27(10.5 \%)$ \\
\hline - $\quad$ Face bow and fork & $162(62.8 \%)$ & $66(25.6 \%)$ & $30(11.6 \%)$ \\
\hline \multicolumn{4}{|l|}{ Do you sterilize (autoclaved) the following items before being used with patient? } \\
\hline - $\quad$ Face bow fork & $219(84.9 \%)$ & $15(5.8 \%)$ & $24(9.3 \%)$ \\
\hline - $\quad$ Fox occlusal plane & $189(73.3 \%)$ & $18(7.0 \%)$ & $51(19.8 \%)$ \\
\hline
\end{tabular}

Table 3. Distribution of responses to questions related to knowledge of study subject towards infection control, and comparison of mean value of their attitude scores in relation to their responses of their knowledge.

\begin{tabular}{|c|c|c|c|c|}
\hline \multirow[t]{2}{*}{ Questions related to knowledge } & \multirow{2}{*}{$\begin{array}{c}\begin{array}{c}\text { Distribution of } \\
\text { responses }\end{array} \\
\text { Total No. }(\%) \\
\end{array}$} & \multicolumn{3}{|c|}{$\begin{array}{l}\text { Comparison of mean value of their responses with their attitude } \\
\text { scores }\end{array}$} \\
\hline & & Mean (SD) & F-value & p-value \\
\hline \multicolumn{5}{|c|}{ Have you had a didactic (theory) lectures about infection control during your under-graduate or internship program? } \\
\hline - No, never had a lecture before & $3(1.2 \%)$ & $9(0)$ & \multirow[t]{5}{*}{7.37} & \multirow[t]{5}{*}{$<0.0001$} \\
\hline - Yes, only few lectures during undergraduate program & $219(84.9 \%)$ & $14.5(3.3 \%)$ & & \\
\hline - Yes, 1 weekly lecture during one semester & -- & -- & & \\
\hline - Yes, 1 weekly lecture during one academic year & $21(8.1 \%)$ & $13.1(2.6 \%)$ & & \\
\hline - More than that & $15(5.8 \%)$ & $11.4(3.0 \%)$ & & \\
\hline \multicolumn{5}{|c|}{ Have you attended a clinical demonstration/ hands on workshop about infection control during your under-graduate program? } \\
\hline - No, never had a training before & $102(39.5 \%)$ & $14.1(3.1 \%)$ & \multirow[t]{4}{*}{1.67} & \multirow[t]{4}{*}{0.17} \\
\hline - $\quad$ Yes, once during the undergraduate program & $138(53.5 \%)$ & $14.3(3.6 \%)$ & & \\
\hline - $\quad$ Yes, twice during the undergraduate program & $12(4.7 \%)$ & $12.7(1.7 \%)$ & & \\
\hline - $\quad$ Yes, every year & $6(2.3 \%)$ & $12.0(3.3 \%)$ & & \\
\hline
\end{tabular}

\section{Discussion}

Measuring attitudes and awareness of practitioners toward infection control in prosthodontic clinic is very important to be conducted in the early years of practice. Enhancing and motivating dental students are essential for them to adopt attitudes and behaviors learned on infection control when they become professional dentists.

This questionnaire evaluated the attitudes and awareness of dental students and interns towards infection control measures in the Prosthodontic Clinic in the College of Dentistry at King Saud University, Saudi Arabia (first dental school in Saudi Arabia) [15]. It also assessed their education and provided self-assessment to their knowledge and implementation of infection control policy in the Prosthodontic Clinic. It is a study with an internal validity, which means the data represents one dental school, not the entire country. Not all infection control procedures were investigated because of concerns that increase number of questions would reduce the accuracy of response and response rate.

Almost two-thirds of the respondents were males. This high percentage of male respondents was due to the large number of male dental students and interns compared to the females. Also, because the males and females are in two separate campuses (due to the Saudi culture and regulations), it was easier for the author (being male) to 
Table 4. Distribution of responses to questions related to satisfaction of study subject with their knowledge and behavior toward infection control, and comparison of mean value of their attitude scores in relation to their responses of their satisfaction with their knowledge and behavior.

\begin{tabular}{|c|c|c|c|c|}
\hline \multirow[t]{2}{*}{ Satisfaction questions } & \multirow{2}{*}{$\begin{array}{c}\begin{array}{c}\text { Distribution of } \\
\text { responses }\end{array} \\
\text { Total No. }(\%)\end{array}$} & \multicolumn{3}{|c|}{$\begin{array}{l}\text { Comparison of mean value of their } \\
\text { responses with their attitude scores }\end{array}$} \\
\hline & & Mean (SD) & F-value & p-value \\
\hline \multicolumn{5}{|c|}{ How do you evaluate your knowledge about infection control in prosthodontic clinic? } \\
\hline - $\quad$ Very poor & -- & -- & \multirow[t]{5}{*}{9.78} & \multirow[t]{5}{*}{$<0.0001$} \\
\hline - $\quad$ Poor & $9(3.5 \%)$ & $14(4.6 \%)$ & & \\
\hline - $\quad$ Fair & $75(29.1 \%)$ & $12.8(3.9 \%)$ & & \\
\hline - Good & $153(59.3 \%)$ & $14.3(2.8 \%)$ & & \\
\hline - $\quad$ Very good & $21(8.1 \%)$ & $17.0(2.65)$ & & \\
\hline \multicolumn{5}{|c|}{$\begin{array}{l}\text { How do you evaluate your implementation of infection control policy in you } \\
\text { prosthodontic clinical practice? }\end{array}$} \\
\hline - Very poor & -- & -- & \multirow[t]{5}{*}{20.39} & \multirow[t]{5}{*}{$<0.0001$} \\
\hline - $\quad$ Poor & $9(3.5 \%)$ & $11.0(3.1 \%)$ & & \\
\hline - $\quad$ Fair & $105(40.7 \%)$ & $12.97(3.7 \%)$ & & \\
\hline - Good & $132(51.2 \%)$ & $14.8(2.6 \%)$ & & \\
\hline - Very good & $12(4.7 \%)$ & $19.0(1.3 \%)$ & & \\
\hline \multicolumn{5}{|c|}{$\begin{array}{l}\text { Are you satisfied with your knowledge and your performance in infection control in } \\
\text { your prosthodontic clinical practice? }\end{array}$} \\
\hline - $\quad$ Not satisfied & $6(2.3 \%)$ & $14.5(3.8 \%)$ & \multirow[t]{5}{*}{8.13} & \multirow[t]{5}{*}{$<0.0001$} \\
\hline - $\quad$ Little satisfied & $27(10.5 \%)$ & $12.5(4.4 \%)$ & & \\
\hline - $\quad$ Fairly satisfied & $93(36 \%)$ & $13.1(3.4 \%)$ & & \\
\hline - $\quad$ Almost satisfied & $111(43 \%)$ & $14.9(2.5 \%)$ & & \\
\hline - Totally satisfied & $21(8.1 \%)$ & $16.5(3.9 \%)$ & & \\
\hline
\end{tabular}

access male students and interns to motivate them to respond to the questionnaire.

HBV immunization among the subjects was $94.2 \%$. Only 6 subjects (out of 258) were not vaccinated, and 9 subjects were not sure if they had it before. Increase number of vaccinated students can be attributed to the strong encouragement and recommendation of the dental school. However, it is not mandatory for completion of registration by the Saudi Commission for Health Specialties [16]. The result of this study proved similar to those carried out in other dental schools. De Souza et al. reported that $90.8 \%$ of all senior students received vaccinations in 6 dental schools in Rio de Janeiro, Brazil [10]. McCarthy and Britton's study showed $100 \%$ immunization among the final year undergraduate dental, medical and nursing students at the University of Western Ontario, Canada [17]. In the Middle East, a previous study completed at the College of Dentistry in Sharjah University reported 95.8\% dental students were vaccinated for HBV [18]. Another study completed at Mashhad Dental School in Iran reported $89.9 \%$ of the students were vaccinated for HBV [19]. In Saudi Arabia, Ahmad et al. stated about $80 \%$ of the dental students and interns in Riyadh College of Dentistry and Pharmacy, Riyadh received an HBV vaccination [20].

Previous study had shown that $20 \%$ of the incidences of hepatitis B developed after needle stick injuries [21]. Sharp injuries are more likely to occur in the dental environment than to other health care settings [22]. This is may be due to the work in small operating fields and dealing with a variety of sharp dental instruments. The previous study by McCarthy and Britton [17] reported $82 \%$ accidental injuries, whereas De Souza et al. [10] in their study reported $31 \%$ accidental injuries. According to the study in Sharjah University, 53.8\% of the dental students reported they had accidental injuries [18]. In our questionnaire, $57 \%$ of the subjects reported that they had sharp injury, and $30.2 \%$ were affected with eye splashing injury.
Regarding the subjects attitudes toward infection control in the Prosthodontic Clinic, most of the students and interns (96.5\%-100\%) care about protective parries (gloves, face mask and protective gown). However, they were less concern in using other protective items $(73.3 \%$ protective glasses and $36 \%$ head cap). This result is comparable to previous studies $[7,18,20]$ were using protective glasses and head cap were low, around $59 \%$ and $40 \%$, respectively. On the other hand, only $53.5 \%-79.1 \%$ of the subjects were aware about disinfecting important items used regularly in the Prosthodontic Clinic (rubber bowl, alginate mixing spatula, face bow and shade guide) which are common items used in the clinic.

For infection control between dental office and dental laboratory, few questions included in the questionnaire were related to disinfecting items sent or received by the dental laboratory. The Centers for Disease Control and Prevention Guideline for Infection Control in Dental Health-Care Settings in 2003 provided different strategies to control infection in the dental clinic and dental laboratory [23]. Risk of infection of laboratory technicians by saliva or blood-borne infections such as HBV has been documented [24]. Therefore, items such as impressions, dental cast, denture prosthesis, metal framework for removable or fixed prosthesis, bite registration or wax rim must be disinfected before they are sent to the dental laboratory [25]. In this study, $96.5 \%$ of the respondents rinse the impression and apply disinfectant before sending it to the dental laboratory. However, only $54.7 \%$ remember to disinfect the outer side of the impression tray. In the previous study by Ahmad et al. [20], 87\% of the subjects disinfect impression before it was sent to the laboratory. Other studies reported less than that, $53.7 \%$ [26] and $18.1 \%$ [27]. On the other hand, around $62.8 \%-68.65 \%$ of the study samples disinfect other dental prosthetic items (denture prosthesis, metal framework for removable or fixed prosthesis, bite registration or wax rim, and face bow and fork) before sending them to laboratory. These results suggested that additional education is required to promote routine disinfection of impressions and prostheses.

In order to facilitate better understanding on how to evaluate awareness on infection control amongst dental students, it was necessary to have a background in their education about control infection in the dental clinic. Two questions related to previous education in infection control during the graduate studies were included in the questionnaire. The findings of this study showed insufficient knowledge among the subjects. Most of them (84.9\%) had only few lectures about infection control during their academic program, and about $93 \%$ had not attended or attended only one clinical demonstration about infection control during their academic program. The result of this study regarding knowledge on infection control is similar to previous studies by Askarian et al. [28] and Abreu et al. [1] on dental students in Iran and Brazil, respectively.

Self-assessment is very important to understand students' satisfaction regarding their attitude towards infection control in the prosthodontic clinic, and the correlation of their satisfaction with their attitude. Most of the subjects evaluated their knowledge and their implementation of infection control policy as "Fair" or "Good", and most of them were fairly satisfied (36\%) or almost satisfied (43\%) with their knowledge and their performance toward infection control policy. These results reflect students' responses according to 5-point ordinal scale in correlation with the quantitative responses of attitude responses toward infection control.

The finding of this study suggested that educational efforts 
are needed to improve dental students' and interns' attitudes and awareness toward infection control in the prosthodontic clinic. It may be recommended to focus on strategies to motivate dental students to implement infection control measures with their routine use. Also, dental schools could offer opportunities for students to analyze their own experiences in the dental clinic from the perspective of infection control. One of the examples is the approach proposed by MachadoCarvalhais et al. [29], as it offers the advantage of sensitizing students to their attitudes in order to change their behavior and consequently improve their quality of life.

Some limitations of the present study should be acknowledged. This questionnaire was conducted in a single institution, and thus the results cannot be generalized to the students and interns of other dental institutions. However, the findings would be useful for planning and implementation of future interventions, including a national survey of dental institutions across the country.

\section{Conclusions}

The findings of this study indicate insufficient attitude and awareness toward infection control, especially for the procedure related to prosthodontic practice. Subjects' responses showed deficiency of education to support infection control measures, and their selfassessment and satisfaction reflect their performance toward infection control policy.

\section{Acknowledgment}

The author is thankful to Dr. Fahim Vohra, Department of Prosthetic Dental Sciences at King Saud University for his help in reviewing and the valuable additions to the questionnaire.

\section{References}

1. Abreu MH, Lopes-Terra MC, Braz LF, Rímulo AL, Paiva SM, et al. (2009) Attitudes and behavior of dental students concerning infection control rules: a study with a10year interval. Braz Dent J 20: 221-225. [Crossref]

2. Taiwo JO, Aderinokun GA (2002) Assessing cross infection prevention measures at the Dental Clinic, University College Hospital, Ibadan. Afr J Med Med Sci 31: 213-217. [Crossref]

3. Scully C, Greenspan JS (2006) Human immunodeficiency virus (HIV) transmission in dentistry. J Dent Res 85: 794-800. [Crossref]

4. Taiwo O1 (2014) Dental practice, human immunodeficiency virus transmission and occupational risks: views from a teaching hospital in Nigeria. Ann Med Health Sci Res 4: S94-98. [Crossref]

5. Milward MR, Cooper PR (2007) Competency assessment for infection control in the undergraduate dental curriculum. Eur J Dent Educ 11: 148-154. [Crossref]

6. Singh A, Purohit BM, Bhambal A, Saxena S, Singh A, et al. (2011) Knowledge, attitudes, and practice regarding infection control measures among dental students in Central India. $J$ Dent Educ 75: 421-427. [Crossref]

7. Freire DN, Pordeus IA, Paixão HH (2000) Observing the behavior of senior dental students in relation to infection control practices. J Dent Educ 64: 352-356. [Crossref]

8. Qudeimat MA, Farrah RY, Owais AI (2006) Infection control knowledge and practices among dentists and dental nurses at a Jordanian university teaching center. Am J Infect Control 34: 218-222. [Crossref]

9. Sofola OO, Folayan MO, Denloye OO, Okeigbemen SA (2007) Occupational exposure to bloodborne pathogens and management of exposure incidents in Nigerian dental schools. J Dent Educ 71: 832-837. [Crossref]

10. de Souza RA, Namen FM, Galan J Jr, Vieira C, Sedano HO (2006) Infection control measures among senior dental students in Rio de Janeiro State, Brazil. J Public Health Dent 66: 282-284. [Crossref]

11. Acosta-Gío AE, Borges-Yáñez SA, Flores M, Herrera A, Jerónimo J, et al. (2008) Infection control attitudes and perceptions among dental students in Latin America: implications for dental education. Int Dent J 58: 187-193. [Crossref]

12. Bhat VS, Shetty MS, Shenoy KK. (2007) Infection control in the prosthodontic laboratory. J Indian Prosthodont Soc 7: 62-65.

13. Connor C (1991) Cross-contamination control in prosthodontic practice. Int $J$ Prosthodont 4: 337-344. [Crossref]

14. Matalon S, Eini A, Gorfil C, Ben-Amar A, Slutzky H (2011) Do dental impression materials play a role in cross contamination? Quintessence Int 42: e124-130. [Crossref]

15. Official web-site of College of Dentistry, King Saud University [Internet]. [cited 2014 Oct 14].

16. Al-Dharrab AA, Al-Samadani KH (2012) Assessment of hepatitis B vaccination and compliance with infection control among dentists in Saudi Arabia. Saudi Med J 33: 1205-1210. [Crossref]

17. McCarthy GM, Britton JE (2000) A Survey of Final-Year Dental, Medical and Nursing Students: Occupational Injuries and Infection Control. J Can Dent Assoc 66: 561. [Crossref]

18. Rahman B, Abraham SB, Alsalami AM, Alkhaja FE, Najem SI (2013) Attitudes and practices of infection control among senior dental students at college of dentistry, university of Sharjah in the United Arab Emirates. Eur J Dent 7: S15-19. [Crossref]

19. Moradi Khanghahi B, Jamali Z, Pournaghi Azar F, Naghavi Behzad M, AzamiAghdash S (2013) Knowledge, Attitude, Practice, and Status of Infection Control among Iranian Dentists and Dental Students: A Systematic Review. J Dent Res Dent Clin Dent Prospects 7: 55-60. [Crossref]

20. Ahmad IA, Rehan EA, Pani SC (2013) Compliance of Saudi dental students with infection control guidelines. Int Dent J 63: 196-201. [Crossref]

21. Wood PR (1992) Cross infection control in dentistry: a practical illustrated guide. Wolfe Pub Ltd.

22. Younai FS, Murphy DC, Kotelchuck D (2001) Occupational exposures to blood in a dental teaching environment: results of a ten-year surveillance study. $J$ Dent Educ 65: 436-448. [Crossref]

23. Centers for Disease Control and Prevention (2004) 2003 CDC infection control recommendations for dental health-care settings. Compend Contin Educ Dent 25: 4348, 50-3. [Crossref]

24. Salvia AC, Matilde Fdos S, Rosa FC, Kimpara ET, Jorge AO, et al. (2013) Disinfection protocols to prevent cross-contamination between dental offices and prosthetic laboratories. J Infect Public Health 6: 377-382. [Crossref]

25. Kohn WG, Harte JA, Malvitz DM, Collins AS, Cleveland JL, et al. (2004) Guidelines for infection control in dental health care settings--2003. J Am Dent Assoc 135: 33-47. [Crossref]

26. Yengopal V, Naidoo S, Chikte UM (2001) Infection control among dentists in private practice in Durban. SADJ 56: 580-584. [Crossref]

27. Al-Omari MA, Al-Dwairi ZN (2005) Compliance with infection control programs in private dental clinics in Jordan. J Dent Educ 69: 693-698. [Crossref]

28. Askarian M, Honarvar B, Tabatabaee HR, Assadian O (2004) Knowledge, practice and attitude towards standard isolation precautions in Iranian medical students. $J$ Hosp Infect 58: 292-296. [Crossref]

29. Machado-Carvalhais HP, Ramos-Jorge ML, Auad SM, Martins LH, Paiva SM, et al (2008) Occupational exposure to potentially infectious biological material in a dental teaching environment. $J$ Dent Educ 72: 1201-1208. [Crossref]

Copyright: $₫ 2015$ Alshiddi IF. This is an open-access article distributed under the terms of the Creative Commons Attribution License, which permits unrestricted use, distribution, and reproduction in any medium, provided the original author and source are credited. 